\title{
Review
}

\section{Christopher R. McCudden* \\ Quality, origins and limitations of common therapeutic drug reference intervals}

https://doi.org/10.1515/dx-2018-0001

Received January 4, 2018; accepted April 24, 2018; previously published online May 24, 2018

\begin{abstract}
Therapeutic drug monitoring (TDM) is used to manage drugs with a narrow window between effective and toxic concentrations. TDM involves measuring blood concentrations of drugs to ensure effective therapy, avoid toxicity and monitor compliance. Common drugs for which TDM is used include aminoglycosides for infections, anticonvulsants to treat seizures, immunosuppressants for transplant patients and cardiac glycosides to regulate cardiac output and heart rate. An essential element of TDM is the provision of accurate and clinically relevant reference intervals. Unlike most laboratory reference intervals, which are derived from a healthy population, TDM reference intervals need to relate to clinical outcomes in the form of efficacy and toxicity. This makes TDM inherently more difficult to develop as healthy individuals are not on therapy, so there is no "normal value". In addition, many of the aforementioned drugs are old and much of the information regarding reference intervals is based on small trials using methods that have changed. Furthermore, individuals have different pharmacokinetics and drug responses, particularly in the context of combined therapies, which exacerbates the challenge of universal TDM targets. This focused review examines the origins and limitations of existing TDM reference intervals for common drugs, providing targets where possible based on available guidelines.
\end{abstract}

Keywords: reference intervals; therapeutic drug monitoring.

\section{Introduction}

Therapeutic drug monitoring (TDM) is defined as the measure of a compound to provide guidance on clinical

\footnotetext{
*Corresponding author: Christopher R. McCudden, PhD, DABCC, FACB, FCACB, Associate Professor, Department of Pathology and Laboratory Medicine, Division of Biochemistry, University of Ottawa, 501 Smyth Rd., Ottawa, ON K1H 8L6, Canada,

Phone: +613-737-8899 Ex.74850, E-mail: cmccudde@uottawa.ca
}

decision-making. TDM is used for a variety of purposes including monitoring compliance, individualizing of therapy, avoiding toxicity, detecting drug interactions, cost-effectiveness and for guidance of therapy discontinuation $[1,2]$. TDM is particularly important for drugs that have narrow therapeutic windows and well-established target concentrations for efficacy.

TDM is used for a number of medications, including aminoglycosides, anticonvulsants, digoxin, lithium and immunosuppressants. For these drugs, the foundation of TDM is that the blood concentration correlates better with efficacy and toxicity than does drug dosage. In addition, clinical signs and symptoms of toxicity may be difficult to identify prior to irreversible damage. While there has been extensive development in the field of pharmacogenomics $[3,4]$ and a growing understanding of pharmacokinetics in varying genetic backgrounds, these evolving fields have largely failed to replace traditional TDM. Currently, TDM retains a wide range of utilities, from titrating the initial dose of immunosuppressants to monitoring compliance. It is essential for assessing toxicity risk when drug clearance mechanisms are affected, such as renal impairment. Traditional use of TDM as a means to differentiate toxicity from disease remains a clinical mainstay.

Despite the clinical utility of TDM and the long history of commonly prescribed therapeutic drugs, there is often limited new information on appropriate target and toxic concentrations (Figure 1). As a result, much of the existing literature and target concentrations used by laboratories and pharmacies are old. There are a wealth of small trials and more recent literature available in selected populations, such as neonates or patients with renal failure, but broad, evidence-based recommendations are limited and randomized control trials are rare or non-existent.

In addition, there are often substantial differences in the results yielded from available commercial methods. Proficiency testing data (where unknown samples are measured and reported by participating laboratories) reveal marked differences between different methods used to measure the same drug. Consider that a drug 


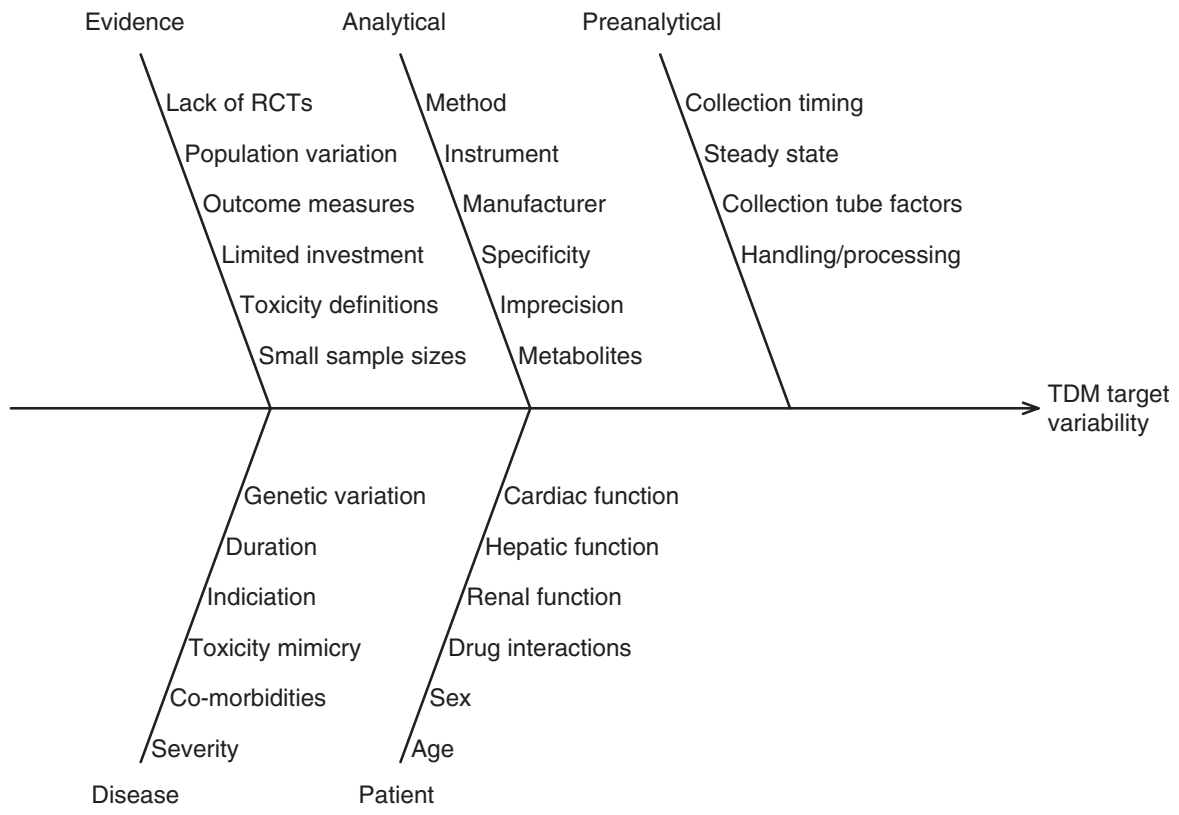

Figure 1: Cause-effect diagram illustrating factors that contribute to the variability of TDM targets. RCTs, randomized control trials.

may be measured by more than half-a-dozen different methods (e.g. various immunoassays, fluorescence polarization or turbidimetry) and there may be as many as five or more vendors for each type of method using a variety of different hardware platforms. For example, there are more than 20 different vendor/method/instrument possibilities for measuring digoxin. Even within the same method, variation may exceed $20 \%$ for a given sample. This variation may be compounded by the variable specificity of proprietary antibodies to metabolites and related compounds.

A further confounding factor with TDM is the common preanalytical error of inappropriate collection timing [5-7]. Inappropriate collection timing refers to drawing trough or peak samples when the drug is not its respective maximum or minimum. Timing errors may also include drawing samples before steady-state concentrations are achieved. Effective drug collection timing requires a knowledge of the particular pharmacokinetics of a given drug, which depends on administration method and halflife of the drug. It is reported that collection times may be inappropriate as much as $70 \%$ of the time [5-7]. This collection timing error translates to an inappropriate dosage indication in up to $60 \%$ of patients. Evidence for effective TDM concentrations in pediatric patients is also typically limited to small trials and case reports. Finally, the broad range of indications for many therapeutic drugs makes a single reference interval difficult if not impossible (consider antibiotic requirements in sepsis vs. a urinary tract infection).
As part of routine quality review, laboratories examine their reference intervals and clinical cutoffs used when reporting results. In this focused review, the methods, sources, limitations and evidence for selected TDM target values including aminoglycosides, antibiotics, anticonvulsants, immunosuppressants, lithium and digoxin are examined and discussed.

\section{TDM methods}

There are numerous different methods used by clinical laboratories to measure therapeutic drugs. With the exception of immunosuppressants and lithium, most methods rely on specific antibodies for measurement (Table 1). Not surprisingly, this long list of what are often proprietary methods results in a general lack of standardization and often substantial differences between results. Lithium, as an element, is measured by colorimetric, spectrophotometric, ion selective electrode and enzyme methods, again showing variation in results. Immunosuppressants are measured by both immunoassays and mass spectrometry, similarly resulting in a wide range of results. The main differences between methods relate to differential detection of metabolites. Metabolite detection is particularly variant between mass spectrometry and immunoassays, the former of which is capable of much better specificity when compared with immunoassays. 
Table 1: Commonly used TDM methods. ${ }^{a}$

\begin{tabular}{|c|c|}
\hline Method & Analyte class \\
\hline Cloned enzyme donor immunoassay (CEDIA) & Anticonvulsants, aminoglycosides, immunosuppressants \\
\hline Chemiluminescent immunoassay $(\mathrm{CIA})$, heterogenous & $\begin{array}{l}\text { Anticonvulsants, cardiac glycosides, aminoglycosides, } \\
\text { antibiotics, immunosuppressants }\end{array}$ \\
\hline Chemiluminescent microparticle immunoassay (CMIA) & $\begin{array}{l}\text { Anticonvulsants, cardiac glycosides, aminoglycosides, } \\
\text { antibiotics, immunosuppressants }\end{array}$ \\
\hline Enzyme immunoassay (EIA), homogenous & Anticonvulsants, cardiac glycosides, aminoglycosides, antibiotics \\
\hline Fluorescence polarization immunoassay (FPIA) & Anticonvulsants, aminoglycosides, antibiotics \\
\hline Immunoturbidimetry & Anticonvulsants, cardiac glycosides, aminoglycosides, antibiotics \\
\hline Kinetic interaction of microparticles in solution (KIMS) & Anticonvulsants, cardiac glycosides, aminoglycosides, antibiotics \\
\hline Latex particle agglutination & Anticonvulsants, cardiac glycosides, aminoglycosides \\
\hline LC-MS/MS & Immunosuppressants \\
\hline Magnetic particle immunoassay & Cardiac glycosides \\
\hline $\begin{array}{l}\text { Particle-enhanced turbidimetric inhibition immunoassay } \\
\text { (PETINIA) }\end{array}$ & $\begin{array}{l}\text { Anticonvulsants, cardiac glycosides, aminoglycosides, } \\
\text { antibiotics, immunosuppressants }\end{array}$ \\
\hline $\begin{array}{l}\text { Spectrophotometry, colorimetric, enzymatic/colorimetric, } \\
\text { ion selective electrode }\end{array}$ & Lithium \\
\hline Enzyme multiplied immunoassay technique (SYVA EMIT) & $\begin{array}{l}\text { Anticonvulsants, cardiac glycosides, aminoglycosides, } \\
\text { antibiotics, immunosuppressants }\end{array}$ \\
\hline
\end{tabular}

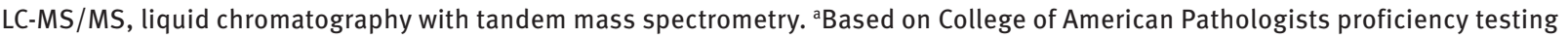
survey data.

\section{Aminoglycosides and antibiotics: amikacin, gentamicin, tobramycin, vancomycin}

Aminoglycosides have long been used to treat infections caused by aerobic Gram-negative bacteria, such as Escherichia coli and Pseudomonas aeruginosa. Aminoglycosides bind to ribosomal subunits, effectively inhibiting bacterial protein synthesis. Aminoglycosides are a broad class of antibiotics, which include amikacin, gentamicin and tobramycin. Although there are newer broad-spectrum drugs, such as $\beta$-lactam antimicrobials, aminoglycosides remain essential for select clinical indications. A discussion of indications is beyond the scope of this review, but common uses include single dose surgery prophylaxis, short duration empirical therapy in severe illness and combination therapy for P. aeruginosa [8].

Toxicity from aminoglycosides includes ototoxicity and renal tubular necrosis. The toxicity profile of common aminoglycosides (amikacin, gentamicin, tobramycin) is reported to vary by drug [9-11], but definitive evidence is lacking [8]. Overall rates of toxicity range from 5 to
$20 \%$ and definitions of toxicity vary [12, 13]. Risk factors for toxicity include high dose, advanced age, volume depletion or dehydration and co-morbidities that affect clearance and metabolism [13]. Unfortunately, the risk of toxicity varies widely between patients and doses [14]. While proximal tubule damage may be reversible over a short time frame, it may become permanent if high blood concentrations are maintained beyond a few weeks; ototoxicity is often irreversible [13]. However, even with short dosing duration and no apparent risk factors toxicity may occur [15].

Aminoglycosides are not well-absorbed when administered orally. They are largely cleared by the kidney and have a short half-life of $2-3 \mathrm{~h}$, low protein binding $(<30 \%)$ and consequently low volume of distribution. For effective treatment, minimum inhibitory concentrations (MICs) need to be reached and maintained. While a discussion of dosing recommendations is beyond the scope of this review, there are fundamentally two main regimens used, conventional and pulse. Conventional dosing involves administration of the drug every 8-12 $\mathrm{h}$ whereas "pulse dosing" (also known as extended interval dosing) involves a wider interval between doses (typically 24-48 h). 
The combination of MIC requirements and toxicity risk is the basis for aminoglycoside TDM. TDM is used to maintain effective bacterial killing concentrations, while limiting the risk of nephrotoxicity and ototoxicity. The combined need to achieve a minimum drug concentration and avoid toxicity necessitates measurement of both minimum and maximum concentrations [16]. Thus, with conventional dosing of aminoglycosides, both peak and trough levels are typically measured. However, there are recommendations that suggest a peak and random timed collection would be more effective for dose adjustments $[8,17]$. For "pulse chase dosing", there have been several nomograms and algorithms [18-20] developed to attempt to improve efficacy and reduce toxicity. Algorithms modify dosing based on the inputs, which include infection type, renal function and co-morbidities. It is noteworthy that bacterial susceptibility is also important for directing minimum dosing. MIC may be used in combination with the area under the curve (AUC) or peak concentrations.

In general, there is some evidence that patients who achieve target concentrations have better outcomes [21, 22]. However, aminoglycosides typically lack evidencebased outcome measures for TDM targets. Despite extensive anecdotal information, case reports and small trials in selected patient groups, there is a lack of randomized control trials and limited support for optimal TDM targets
[23]. Collectively, the evidence for TDM target concentrations for aminoglycosides is complex and varied, making concise universal recommendations difficult. The involvement of clinical pharmacology, assurance of accurate data (e.g. time of collection and dosing) and recognition of risk factors (e.g. renal impairment) are all important considerations for aminoglycoside TDM.

\section{Amikacin}

There is limited evidence-based data on the appropriate TDM targets for amikacin [23]. Of the existing trials, most fail to either define target concentrations or monitor if those concentrations were achieved. Older retrospective case literature supports $>80 \%$ treatment efficacy rates [24], with an associated $20 \%$ of patients with side effects, such as ototoxicity and nephrotoxicity.

Where evidence is available [23], target concentrations are highly variable, ranging from troughs between 2 and $30 \mathrm{mg} / \mathrm{L}$ and peaks between 15 and $40 \mathrm{mg} / \mathrm{L}$ (Table 2). It is reported that trough concentrations $>8 \mathrm{mg} / \mathrm{L}$ and peak concentrations $>32 \mathrm{mg} / \mathrm{L}$ are associated with ototoxicity and nephrotoxicity [12]. Generally, recommendations for desirable serum concentrations range from 1 to $10 \mathrm{mg} / \mathrm{L}$ for trough concentrations, and from 20 to $40 \mathrm{mg} / \mathrm{L}$ for peak concentrations [12, 23] (Table 1).

Table 2: TDM reference intervals for common drugs.

\begin{tabular}{|c|c|c|c|c|}
\hline Drug & Collection timing & Reference interval $^{\mathrm{a}}$ & Critical value & Recommended collection time \\
\hline \multirow[t]{3}{*}{ Amikacin } & Trough & $1-10 \mathrm{mg} / \mathrm{L}$ & $>10 \mathrm{mg} / \mathrm{L}$ & Within 30 min of next dose \\
\hline & Peak & $20-40 \mathrm{mg} / \mathrm{L}$ & $>40 \mathrm{mg} / \mathrm{L}$ & $\begin{array}{l}30-60 \text { min post I.V. infusion } \\
60-90 \text { min post I.M. injection }\end{array}$ \\
\hline & Random & None & $>10 \mathrm{mg} / \mathrm{L}$ & - \\
\hline Carbamazepine & - & $17-51 \mu \mathrm{mol} / \mathrm{L}$ & $>60 \mu \mathrm{mol} / \mathrm{L}$ & Trough \\
\hline \multirow[t]{2}{*}{ Digoxin } & - & $1.0-2.6 \mathrm{nmol} / \mathrm{L}$ & $>3.2 \mathrm{nmol} / \mathrm{L}$ & $6-10 \mathrm{~h}$ post dose \\
\hline & & $0.6-1.3 \mathrm{nmol} / \mathrm{L}$; heart failure & & \\
\hline \multirow[t]{3}{*}{ Gentamicin/tobramycin } & Trough & $<2 \mathrm{mg} / \mathrm{L}$ & $>2 \mathrm{mg} / \mathrm{L}$ & Within $30 \mathrm{~min}$ of next dose \\
\hline & Peak & $5-12 \mathrm{mg} / \mathrm{L}$ & $>12 \mathrm{mg} / \mathrm{L}$ & - \\
\hline & Random & None & $>12 \mathrm{mg} / \mathrm{L}$ & - \\
\hline Lithium & - & $\begin{array}{l}0.6-0.8 \mathrm{mmol} / \mathrm{L} \text {; bipolar disorder } \\
\text { maintenance } \\
1.0-1.2 \mathrm{mmol} / \mathrm{L} \text {; acute mania } \\
0.4-0.8 \mathrm{mmol} / \mathrm{L} \text {; age } \geq 65\end{array}$ & $>1.5 \mathrm{mmol} / \mathrm{L}$ & $\begin{array}{l}12 \mathrm{~h} \text { post-dose during steady } \\
\text { state }\end{array}$ \\
\hline Phenobarbital & - & $43-172 \mu \mathrm{mol} / \mathrm{L}$ & $>200 \mu \mathrm{mol} / \mathrm{L}$ & Trough \\
\hline Phenytoin & - & $40-80 \mu \mathrm{mol} / \mathrm{L}$ & $>100 \mu \mathrm{mol} / \mathrm{L}$ & Trough \\
\hline Valproic acid & - & $350-700 \mu \mathrm{mol} / \mathrm{L}$ & $>1000 \mu \mathrm{mol} / \mathrm{L}$ & Trough \\
\hline \multirow[t]{3}{*}{ Vancomycin } & Trough & $10-20 \mathrm{mg} / \mathrm{L}$ & $>20 \mathrm{mg} / \mathrm{L}^{\mathrm{b}}$ & Within 30 min of next dose \\
\hline & Peak & None & - & Not recommended \\
\hline & Random & None & $>20 \mathrm{mg} / \mathrm{L}$ & Not recommended \\
\hline
\end{tabular}

avalues refer to total drug concentration (not free). ${ }^{\mathrm{b}}$ Critical value may be higher based on more recent evidence, but will be patient-specific. 
Amikacin displays substantial inter-laboratory variability, where measurements between different methods yield different results on the same sample. Based on external proficiency testing data from the College of American Pathologists (CAP), amikacin values differ by $5-20 \%$ between methods. Using the desirable concentrations mentioned above, these would translate to a maximum range of trough concentrations between $<1$ and $12 \mathrm{mg} / \mathrm{L}$ (target $1-10 \mathrm{mg} / \mathrm{L}$ ) and peak concentrations between 16 and $48 \mathrm{mg} / \mathrm{L}$ (target 20-40 mg/L).

\section{Gentamicin}

As with other aminoglycosides, gentamicin is typically used to treat infections caused by Gram-negative bacteria. This includes respiratory and urinary tract infections amongst several others. It too can cause toxicity to the kidney and inner ear. Despite the use of TDM to avoid toxicity, there are reports of renal damage after single dose of gentamicin $[15,25]$. While some of these are transient, permanent damage can occur after a single dose. Efforts to reduce toxicity include development of models and algorithms for gentamicin dosing [26]. There are numerous clinical practice guidelines for different infections, including endocarditis, meningitis, pneumonia, sepsis and prophylaxis [27-30].

For conventional dosing, trough target concentrations aim for values $<2 \mathrm{mg} / \mathrm{L}$ (Table 1 ). Generally recommended values are $<1 \mathrm{mg} / \mathrm{L}$, but rise to $2 \mathrm{mg} / \mathrm{L}$ with life-threatening infection. For peak concentrations, targets are $4-6 \mathrm{mg} / \mathrm{L}$ for urinary tract infections or pyelonephritis [31]. With serious or life-threatening infections, target concentration ranges rise to $6-10 \mathrm{mg} / \mathrm{L}$ [31], though these are variable and as high as $8-12 \mathrm{mg} / \mathrm{L}$ [13]. Disease-specific targets have been recommended, for example, trough targets of $<1 \mathrm{mg} / \mathrm{L}$ for combination therapy in infective endocarditis [27].

As with other analytes, gentamicin displays substantial inter-laboratory variability. Based on external proficiency testing data from CAP, gentamicin values differ by $\sim 15-26 \%$ between methods. Using the target concentrations mentioned above, these would translate to a range of up to $2.5 \mathrm{mg} / \mathrm{L}$ for trough concentrations (versus target of $<2 \mathrm{mg} / \mathrm{L}$ ) and $2.9-7.6 \mathrm{mg} / \mathrm{L}$ compared with $4-6 \mathrm{mg} / \mathrm{L}$ for peak concentrations for serious infection.

\section{Tobramycin}

Tobramycin is another aminoglycoside used to treat infections caused by P. aeruginosa, E. coli and other
Gram-negative bacteria. Tobramycin displays nephroand ototoxicity requiring TDM. Tobramycin is cleared by the kidneys and renal impairment is a risk factor for toxicity. Similar to other aminoglycosides, high doses over a prolonged period are associated with toxicity [32]. While evidence is not definitive, some reports suggest that tobramycin is less toxic than gentamicin [10]. As with other aminoglycosides, tobramycin may be administered conventionally or as a "pulse" or extended dosing, where pulse dosing is thought to reduce toxicity [33].

Despite the possible difference in toxicity, trough and peak targets are largely similar to gentamicin with trough targets typically $<2 \mathrm{mg} / \mathrm{L}$ and peak targets of $<10 \mathrm{mg} / \mathrm{L}$ [12] (Table 1). In addition to generic targets, numerous studies have also examined disease-specific cutoffs, such as for cystic fibrosis, hemodialysis and burn patients amongst others [34-36].

Tobramycin displays substantial inter-laboratory variability. Based on external proficiency testing data from CAP, tobramycin values differ by as much as $\sim 25-49 \%$ between methods. Using the target concentrations mentioned above, these would translate to a range of up to $2.9 \mathrm{mg} / \mathrm{L}$ of for trough concentrations (target of $<2 \mathrm{mg} / \mathrm{L}$ ) and a range of $5.1-14.9 \mathrm{mg} / \mathrm{L}$ at a target of $10 \mathrm{mg} / \mathrm{L}$ for peak concentrations. This wide range of potential results between methods highlights the limitations of general targets for TDM for aminoglycosides.

\section{Vancomycin}

Vancomycin is a complex peptide discovered in the 1950s. It was named for its ability to "vanquish" staphylococci bacterium, which is resistant to penicillin [37]. It is effective against many strains of microorganisms including Clostridium difficile, Listeria monocytogenes, Streptococcus pyrogenes and Streptococcus pneumoniae. Currently, it is essential for treatment of methicillin-resistant Staphylococcus aureus (MRSA) infections. It may also be used for C. diff colitis.

While effective as an antibiotic, early use of vancomycin revealed a narrow therapeutic window with potential for nephrotoxicity and ototoxicity. While debate is ongoing, more recent evidence suggests that toxicity is unlikely at conventional doses, particularly when used as a single agent $[38,39]$. Thus, the utility of measuring vancomycin in serum is evolving primarily to ensure the MIC is reached (and to calculate AUC) as much as to avoid toxicity.

As an early source of vancomycin TDM targets, Geraci [40] recommended peak serum vancomycin 
concentrations of $30-40 \mathrm{mg} / \mathrm{L}$ and trough concentrations of 5-10 mg/L in the 1970s. Unlike many of the other drugs discussed in this review, there are recent guidelines on TDM targets for vancomycin [41]. According to the joint 2009 guidelines, the older recommendation of 5-10 mg/L is too low to reach the MICs for many types of infection. The guidelines recommend that trough vancomycin concentrations should be higher than $10 \mathrm{mg} / \mathrm{L}$ to reduce development of resistance. For complicated infections caused by $S$. aureus (bacteremia, hospital-acquired, ventilator associated and health-care associated pneumonia), the guidelines recommend that trough serum vancomycin concentration should be maintained at $15-20 \mathrm{mg} / \mathrm{L}$. Serum concentrations are commonly used as a surrogate marker for AUC.

As far as timing of sample collections, there is a recommendation against using peak serum vancomycin concentrations to monitor efficacy [41]. This reflects the time-dependent kinetics of vancomycin on bacterial killing, where cure rates are independent of peak concentration. Trough serum vancomycin concentrations are considered the most accurate and practical method for monitoring the effectiveness of vancomycin. For patients on vancomycin monotherapy, monitoring for ototoxicity is not recommended [41].

Collectively, from the laboratory standpoint, a single reference interval (therapeutic interval) of $10-20 \mathrm{mg} / \mathrm{L}$ is appropriate for trough vancomycin measurements. Values above $20 \mathrm{mg} / \mathrm{L}$ should be denoted as high by laboratories. Clinicians monitoring results should be aware of the risks of toxicity in patients with renal instability, cases of multidrug therapy and if a high concentration $(>15 \mathrm{mg} / \mathrm{L})$ is targeted for $>5$ days.

Other considerations for toxicity include infusion rates and protein-binding. Vancomycin is $30-60 \%$ protein-bound, such that patients with decreased albumin have higher bioavailability. In addition, vancomycin is given parenterally because of its low bioavailability, and toxicity may be reduced with slower infusion rates.

In terms of inter-assay consistency, vancomycin results differ from 9 to $29 \%$ depending on the concentration. This translates to a lower cutoff of 7.1-12.9 (at $10 \mathrm{mg} / \mathrm{L}$ ) and an upper cutoff of $19.1-20.9 \mathrm{mg} / \mathrm{L}$ (at $20 \mathrm{mg} / \mathrm{L}$ ). The Institute for Quality Management in Healthcare (IQMH) proficiency testing program allows for up to a 2-mg/L difference at concentrations below $10 \mathrm{mg} / \mathrm{L}$ and up to $20 \%$ at concentrations above $10 \mathrm{mg} / \mathrm{L}$, which equate to a lower cutoff of 8-12 and an upper cutoff of $16-24 \mathrm{mg} / \mathrm{L}$. Clinical users of vancomycin should be aware of these ranges and the limitations of the assay when monitoring patients.

\section{Anticonvulsants: carbamazepine, phenobarbital, phenytoin, valproic acid}

Anticonvulsants, also known as anti-epileptic drugs (AEDs), are widely used to control seizures.

There are three generations of anticonvulsants, the first developed in the early 1910s (e.g. phenobarbital), the second generation appeared in the 1990s (e.g. lamotrigine) and the third generation started in 2008 (e.g. lacosamide). The primary benefits of newer drugs are the reduction in side effects, though clinical efficacy is not better than older drugs [42]. This section focuses on reviewing the first generation drugs including carbamazepine, phenobarbital, phenytoin and valproic acid.

First generation anticonvulsants have been highly effective at treating seizures for decades. The advantages of first generation anticonvulsants are the wealth of knowledge about mechanisms of action and their lack of neuropsychiatric side effects [43]. However, they have undesirable side effects and pharmacokinetic characteristics [44]. Most act on ion channels or neurotransmitter transport in the brain. Side effects include motor impairment, liver damage and abnormal blood counts. Undesirable pharmacokinetic characteristics include zero-order kinetics, high protein binding and metabolism by cytochrome P450 (CYP450). Zero-order kinetics refers to the drug being cleared independent of its concentration (linear); effectively zero-order kinetics makes it more difficult to manage blood concentrations. High protein binding, as occurs with phenytoin, is difficult to manage because only free drug levels are bioactive and measurement is more challenging. Clearance by CYP450 is not ideal because this enzyme is required for many other processes, which can result in liver damage and interactions [45]. In addition, CYP450 may be either induced or inhibited by different anticonvulsants. Despite these undesirable features, first generation anticonvulsants are clinically effective, remain in wide use and require TDM. As with other drugs, TDM is used for anticonvulsants because the blood concentration correlates better with response than dose [46]. TDM is used for anticonvulsants to avoid toxicity, monitor compliance and ensure effective therapy.

As with many of the other drugs described in this review, there are a limited number of clinical trials and it is unclear what the benefit of TDM is, let alone drug target concentrations.

Because there are many newer drugs available, there tend to be limited new research and clinical trials on older anticonvulsants. While there are some data on 
comparative effective of different anticonvulsants for various types of seizure [47], pharmaceutical companies tend not to invest in agents that are not patent protected [48]. Other challenges with TDM are the lack of targets due to variability in patient response, drug-drug interactions and the effect of co-morbidities on metabolism and toxicity. Moreover, at least half of patients are on more than one drug [49]. For anticonvulsant TDM, interassay variability is also a challenge. Despite recognition of this issue in the 1970s [50], current methods still vary substantially and are not necessarily interchangeable between laboratories. Preanalytical factors, such as collection time and tube type, also contribute to variability [51]. Data are limited in pediatric patients, though there are selected population dosage recommendations, which are generally lower [52, 53]. Anticonvulsants are typically collected prior to the next dose (trough), though those with very long half-lives (phenobarbital) may be collected any time after a steady state is reached. An excellent review by Patsalos et al. [46] details the many limitations and provides best practices for the all three generations of anticonvulsants.

\section{Carbamazepine}

Approved for clinical use in the 1970s, carbamazepine is used to treat partial and generalized tonic-clonic seizures; it is also used to treat trigeminal neuralgia. It is structurally, but not functionally, related to tricyclic antidepressants, though it is sometimes used in manic-depressive patients. Side effects include stupor, coma, diplopia, headache and dizziness. Similar to phenytoin, carbamazepine blocks sodium channels preventing proliferation of action potentials in depolarized neurons [42].

Carbamazepine has $70-100 \%$ oral bioavailability with a half-life of $12-55 \mathrm{~h}$. Carbamazepine potentiates several CYP enzymes (CYP1A2, CYP2C9 and CYP2C19), effectively reducing the concentration of many other drugs that are metabolized by these enzymes [49].

Carbamazepine is almost exclusively metabolized by the liver, primary through oxidation by CYP3A4. The predominant metabolite is carbamazepine-10,11-epoxide, which is as bioactive as the parent drug; this metabolite may accumulate when the patient is on other drugs which affect clearance [43] or in cases of renal impairment [54]. The accumulation of the epoxide metabolite should be considered in cases of apparent toxicity when the parent drug is within the reference interval.

Therapeutic reference intervals are typically in the range of $17-50 \mu \mathrm{mol} / \mathrm{L}(4-12 \mu \mathrm{g} / \mathrm{mL})$ with a toxic limit of $>60 \mu \mathrm{mol} / \mathrm{L}(15 \mu \mathrm{g} / \mathrm{mL})[37,42]$. There are several trials that compare carbamazepine with other anticonvulsants [55-57], yielding effective therapeutic concentrations that generally agree with these targets. For example, one double-blind comparison between phenytoin and carbamazepine to treat long-term poorly controlled seizures $(n=25)$ had a range of concentrations from 25 to $51 \mu \mathrm{mol} / \mathrm{L}$ [56]. Recent guidelines endorse these intervals [58]. As stated above, where symptoms of toxicity manifest at therapeutic concentrations, it is important to consider the epoxide metabolite, which is typically not detected with commercial immunoassays [59].

Carbamazepine displays substantial inter-laboratory variability. Based on external proficiency testing data from CAP, carbamazepine values differ by $\sim 12-32 \%$ between methods. Using the reference intervals mentioned above, drug reference intervals would range from 11 to $62 \mu \mathrm{mol} / \mathrm{L}$ at a target concentration of $17-47 \mu \mathrm{mol} / \mathrm{L}$.

\section{Phenobarbital}

Phenobarbital was one of the first anticonvulsants discovered and was approved for use in 1939. It is used for partial and generalized tonic-clonic and myoclonic seizures. Side effects include sedation, mood alteration and hyperactivity. Phenobarbital enhances the activity of gamma-aminobutyric acid (GABA). Phenobarbital is $>95 \%$ bioavailable orally with roughly $50-60 \%$ of phenobarbital being protein-bound. It has a long and variable half-life of 50-150 h [42], which differs between patients. Phenobarbital is partially cleared by the kidney and predominantly metabolized by CYP2C9 in the liver. In the liver, it promotes metabolism of itself and other drugs through enhancement of CYP3A4 and CYP2C activity.

Targets for phenobarbital blood concentrations are typically listed as between 43 and $172 \mu \mathrm{mol} / \mathrm{L}(10-40 \mathrm{mg} / \mathrm{L})$ $[60,61]$, but there is limited evidence to support either the toxicity or efficacy at these concentrations [50]. Limited evidence suggests that efficacy relates to the seizure type. Toxicity is reported to manifest above $215 \mu \mathrm{mol} / \mathrm{L}$ [62], though lower concentrations may be toxic in some patients. Phenobarbital is used for seizures in neonates, despite target concentrations not being evidence-based. Two studies of pharmacokinetics used $43-130 \mu \mathrm{mol} / \mathrm{L}$ $(10-30 \mathrm{mg} / \mathrm{L})$ as the target range $[61,63]$.

Phenobarbital displays substantial inter-laboratory variability. Based on external proficiency testing data from CAP, phenobarbital values differ by $\sim 18-26 \%$ between methods. Using the reference intervals mentioned above, drug reference intervals would range from 35 to $216 \mu \mathrm{mol} / \mathrm{L}$ (at a target range of $43-172 \mu \mathrm{mol} / \mathrm{L}$ ). 


\section{Phenytoin}

Similar to phenobarbital, phenytoin is another of the first anticonvulsants to be approved for clinical use. It is used as a first-line treatment for partial and generalized tonicclonic and myoclonic seizures. Phenytoin is also used as an analgesic [64]. Side effects of phenytoin include rashes, anemia, neuropathy, balance impairment, fatigue and pseudolymphoma. Phenytoin acts by blocking sodium channels, inhibiting proliferation of action potentials [42]. Phenytoin has high oral bioavailability and high protein binding (80-90\%). Predicting blood concentrations from the dose is particularly challenging [65]. A small portion is cleared by the kidney, but the majority is metabolized by the liver, primary through CYP2C9 and CYP2C19; the major inactive metabolite is parahydroxyphenyhydantoin. The half-life is highly variable between individuals and with dose (30-100 h), as clearance is readily saturated at therapeutic concentrations $>40 \mu \mathrm{mol} / \mathrm{L}$. As with other anticonvulsants, phenytoin potentiates several CYP enzymes (CYP1A1, CYP2C9 and CYP2C1), effectively reducing the concentration of many other drugs that are metabolized by these enzymes (valproic acid, antimicrobials, immunosuppressants, steroids, cardioactive drugs). Dosing is complicated by the interactions between drugs that affect protein binding, bioavailability and metabolism $[46,49]$.

As with most of the drugs discussed in this review, there is limited randomized control trial evidence for TDM $[66,67]$. Existing evidence tends to be old with small sample sizes, and the methods used to measure phenytoin may differ from those used currently. The therapeutic concentration typically encountered is between 40 and $80 \mu \mathrm{mol} / \mathrm{L}$ (10-20 mg/L), with toxic concentrations occurring above $80 \mu \mathrm{mol} / \mathrm{L}(20 \mathrm{mg} / \mathrm{L})$; concentrations above $200 \mu \mathrm{mol} / \mathrm{L}$ may induce coma [68]. There are reports of blood concentration as high as $400 \mu \mathrm{mol} / \mathrm{L}$, which the patient survived [69]. Therapeutic reference intervals should be considered as rough estimates as toxicity may occur at these levels and clinical efficacy may be achieved at lower doses [7072]. One study of phenytoin concentrations and patient response to therapy showed a poor correlation, leading the authors to conclude that the value of therapeutic reference intervals for phenytoin is limited [71].

Because of its high protein-binding, measurement of total phenytoin may be misleading, particularly where other drugs are present or serum protein levels are affected [64]. Free drug levels are useful in situations where there are multiple drugs used or protein levels are altered; free drug concentrations are reported to correlate better with efficacy [73-75]. One aspect that has improved over time is the specificity of phenytoin measurement methods. Older methods were reported to show interference with metabolites in patients with renal failure, but at least some newer methods appear to be robust [76]. However, there are still methodological differences for phenytoin. A older report on commercial methods identified variation between a reference method [high-performance liquid chromatography (HPLC)] and immunoassays to range from 12 to $83 \%$, indicating huge differences between methods [77]. While there are many newer methods that have been developed to measure phenytoin [78-80], most laboratories still rely on commercial immunoassays. These newer assays are better than earlier reports, but still show substantial variation with coefficients of variation (CVs) from 13 to $36 \%$; based on CAP data, the mean variation ranges from $13 \%$ at low concentrations $(10 \mu \mathrm{mol} / \mathrm{L})$ to $36 \%$ at a concentration of $80 \mu \mathrm{mol} / \mathrm{L}$.

\section{Valproic acid}

Valproic acid was approved for clinical use in the 1970s and is used to treat patients with all types of seizures, particularly those resistant to ethosuximide. It is often used as a combination therapy with other anticonvulsants for complex seizure disorders. Valproic acid acts by increasing the concentration of GABA in the brain [42]. It is nearly completely orally bioavailable with a short halflife ( $8-15 \mathrm{~h}$ ) requiring frequent dosing. Side effects include anorexia, nausea, sedation and ataxia [42, 46].

Due to the high extent of protein binding, some investigators have advocated for measurement of free valproic acid. There are several case reports demonstrating toxicity with unremarkable total valproic acid, but highly elevated free valproic acid in patients with hypoalbuminemia [8183]. Despite the potential utility of these measurements, free valproic acid measurement is not commonly available in clinical laboratories.

Typical therapeutic targets for valproic acid are 346-693 $\mu \mathrm{mol} / \mathrm{L}$ (50-100 mg/L), with toxicity occurring at $\geq 693-1390 \mu \mathrm{mol} / \mathrm{L}(100-250 \mathrm{mg} / \mathrm{L})[37,46]$. These values are largely based on small clinical trials, which demonstrated effective seizure control with sample sizes as small as 13 patients $[67,84-86]$. Guidelines recommend individualizing therapy to ensure appropriate valproic acid concentrations [46], collecting trough samples.

CAP data indicate variation between methods. There are 12 different methods to measure valproic acid with mean differences ranging from 20 to $28 \%$ depending on the concentration. Using the aforementioned reference interval of 346-693 $\mu \mathrm{mol} / \mathrm{L}$, the range of possible values obtained by different methods is $249-887 \mu \mathrm{mol} / \mathrm{L}$. 


\section{Immunosuppressants}

Immunosuppressants are widely used in transplant patients to prevent organ rejection. They are also employed for treatment of autoimmune diseases. Immunosuppressants are broadly classified into corticosteroids (e.g. dexamethasone), antimetabolic agents (e.g. mycophenolate), calcineurin inhibitors (e.g. cyclosporine), rapamycin inhibitors (e.g. sirolimus) and monoclonal antibodies (e.g. infliximab). Most of these therapies do not meet the criteria for TDM, such that only a few are subject to routine clinical measurement. Immunosuppressant TDM drugs typically include cyclosporine, tacrolimus, sirolimus, mycophenolic acid and everolimus. These drugs are employed for a variety of transplant and immunosuppressive modalities. Modalities include heart, kidney, liver and lung transplants, which all have various target values which are dependent on drug, formulation (e.g. long or slow release), patient risk factors, time posttransplant, organ(s) and drug combination. As such, a complete description of the target values is beyond the scope of this mini-review; the interested reader may seek these references: [87-89]. However, the issue of methodological differences remains a significant issue for immunosuppressants, which is worthwhile to highlight.

As with other TDM targets, there are numerous different methods employed for measuring immunosuppressants (Table 1). Accordingly, results vary widely between instrumentation due to differential specificity toward target compounds and drug metabolites. In particular, the antibodies used for immunosuppressant immunoassays all typically have some cross-reactivity with many drug metabolites. Unlike other TDM targets, liquid chromatography with tandem mass spectrometry (LC-MS/MS) is used by a significant proportion of laboratories (26-43\% depending on the analyte based on CAP survey data from 2017). LC-MS/MS, as a newer methodology [90], is able to differentiate metabolites from the parent compound enabling much better analytical specificity and measurement accuracy [91-93].

Despite improved analytical performance and extensive development efforts [92, 94], standardization of LC-MS/MS remains problematic [88, 89]. Methodological differences are well-described in an excellent review of the current state of TDM [88]; the review describes variation of $20 \%$ between LC-MS/MS assays and up to $30 \%$ between various immunoassays, as well as the innumerable variables that contribute to assay quality and differences in practice. In short, immunosuppressants have a complex set of targets and assay variation remains a problem for managing patients toward these targets.

\section{Lithium}

Lithium has been used for treatment-resistant major depressive disorder and bipolar disorder for some 50 years. The origin of lithium as a therapeutic agent is interesting in that is was initially conceived as a treatment for gout. While lithium was ineffective for gout and highly toxic at the concentrations used, animal experiments identified its calming effects [95, 96]. Remarkably, the mechanism of action is still unknown, though potential explanations include modulation of neurotransmitters, such as norepinephrine and serotonin, modulation of cyclic adenylyl cyclase and stabilization of neuroprotective proteins, among several others [97].

Lithium is usually provided as $\mathrm{Li}_{2} \mathrm{CO}_{3}$, though lithium citrate is also widely available. As a simple ion, lithium is absorbed completely orally with $80-100 \%$ bioavailability [98]. Eliminated by the kidneys, lithium has a long halflife that is renal function dependent [99], ranging from 18 to $36 \mathrm{~h}$ [100]. In general, side effects from lithium are common, occurring in some $70-90 \%$ of patients when given as monotherapy. In polypharmacy, this rate is likely even higher [101, 102]. Side effects are numerable and include polyuria, polydipsia, hypothyroidism, cognitive impairment, weight gain, tremor, diarrhea, sexual dysfunction, psoriasis and hypercalcemia [101].

Lithium has a narrow therapeutic window, and may be toxic at concentrations $>1.5 \mathrm{mmol} / \mathrm{L}$. Signs of toxicity include drowsiness, nausea, diarrhea, tremors, ataxia and confusion [101]. Importantly, lithium toxicity risk is increased in the elderly as their renal function declines with age.

There are numerous guidelines for lithium treatment globally, including the USA, UK, Canada, Japan, Australia/New Zealand, South Africa and Taiwan [103]. Recommendations vary, but according to the American Psychiatric Association (APA) guidelines [104], therapeutic targets for lithium are $0.5-1.2 \mathrm{mmol} / \mathrm{L}$ for acute mania and $0.6-1.0 \mathrm{mmol} / \mathrm{L}$ for maintenance. For bipolar disorder, targets are almost universally $0.6-0.8 \mathrm{mmol} / \mathrm{L}$ [103]. Plasma concentrations below $0.4 \mathrm{mmol} / \mathrm{L}$ are ineffective for treatment [104]. Toxicity generally occurs at concentrations $>1.5 \mathrm{mmol} / \mathrm{L}$, with severity increasing to the risk of death at concentrations $>3.5 \mathrm{mmol} / \mathrm{L}$.

Guidelines vary, but lithium monitoring is typically recommended at least every 6 months [104]. Samples should be collected $\sim 12 \mathrm{~h}$ post-dose, and a steady state should be reached before measuring $(\sim 1$ week after initiation or dosage adjustment) [98]. Because of the risks to renal function, measurement of urea and creatinine at regular intervals (2-3 months at initiation, yearly thereafter) is 
recommended. Other recommended laboratory measurements include thyroid testing, electrolytes, complete blood count (CBC) and human chorionic gonadotropin (hCG) because of potential side effects and risk to fetus.

Special considerations are needed for pregnancy, children and the elderly. Generally, avoidance of lithium during pregnancy is recommended, by tapering off the dose and substitution with other anti-psychotics [104]. However, in instances where other agents are ineffective, lithium may be given with discussion and consideration of potential teratogenicity. Higher frequency monitoring is recommended if lithium is given during pregnancy, including fetal echocardiograms [104]; again specific guidelines are variable and evidence is lacking. Some recommendations are trimesterspecific [e.g. increasing dose in the last trimester to account for the increased glomerular filtration rate (GFR)] and lactation is contraindicated for patients on lithium. In children, recommendations for treatment of bipolar disorder are again highly variable, ranging from nothing to applying adult dosing; evidence is once again sparse for this population. For the elderly, guidelines are inconsistent. An excellent review of guidelines recommends a lower therapeutic plasma concentration, but evidence is lacking and a specific value was not provided [104]. Several authors do provide discrete targets of $0.4-0.8 \mathrm{mmol} / \mathrm{L}[105,106]$.

Based on CAP proficiency testing survey data, there are markedly different results yielded by various instruments. The mean variability between methods ranges up to $30-75 \%$. The variability would effectively widen the therapeutic reference interval to $0.2-2.1 \mathrm{mmol} / \mathrm{L}$ (from 0.8 to $1.2 \mathrm{mmol} / \mathrm{L}$ ). This huge variability could potentially lead to significant toxicity at high concentrations or potential treatment failure at apparent therapeutic levels of lithium. Standardization of lithium methods is needed as the interassay analytical variability remains very high even within a particular class of assay (e.g. colorimetric).

\section{Digoxin}

Digoxin is a cardiac glycoside with a long and interesting history. Digoxin is derived from the foxglove plant Digitalis $\mathrm{sp}$. It is used to manage heart failure and cardiac arrhythmias. It acts to increase cardiac output and normalize ventricular pulse rate by inhibiting sodium-potassium ATPase in myocardial cells [107].

The side effects of digoxin are perhaps most famously exemplified by the color distortions characteristic of Van Gogh's “Starry night” painting $[108,109]$. Other side effects include nausea, vomiting and cardiac symptoms of ventricular fibrillation and premature ventricular contractions.
Toxicity is notably affected by electrolyte concentrations; specifically, hypokalemia and hypomagnesemia increase the response to digoxin [107, 110, 111]. Treatment for toxicity involves administration of specific antibody fragments (digoxin-Fab), which has been shown to be safe and effective [112]. Despite the long history of clinical use of digoxin, there remains a debate as to the risk-benefit tradeoffs [113, 114]. A recent systematic review concluded that there was no effect on mortality, but a reduction in hospital admission in patients given digoxin for atrial fibrillation and heart failure [115]. Fundamentally, well-designed randomized control trials are needed to definitively conclude whether digoxin benefits outweigh the toxicity risks [116].

Digoxin has high oral bioavailability, but this can be affected by other drugs and gastrointestinal factors, such as bacteria and the presence of food [117]. The half-life of digoxin is $36-48 \mathrm{~h}$, which is prolonged substantially in renal impairment to $2-5$ days. In particular, dosages should be reduced in patients with renal impairment to reduce toxicity [118]. In addition, serum potassium and creatinine measurements should be taken when increasing dosage or changing interacting drugs [119]. Some immunoassays show cross-reactivity with "digoxin-like immunoreactive substances", which are produced in neonates, patients with liver failure or renal impairment and pregnant women [120]. These can falsely elevate digoxin measurements, though some newer methods are more resistant to this type of interference [121, 122]. Unlike other drugs, sample collection timing is based on the peak tissue concentration rather than trough or peak blood levels; this generally translates to a collection time of $\sim 6-10 \mathrm{~h}$ after a dose.

Analytical measurement of digoxin after treatment with digoxin-Fab for toxicity can be inaccurate due to cross-reactivity with reagents and Fab fragments [123]. This interference may be avoided by delaying collection after treatment. Alternatively, free digoxin measurement can resolve the interference by removing the offending protein fragments [123-125].

Commonly cited therapeutic reference intervals for digoxin are $1.0-2.6 \mathrm{nmol} / \mathrm{L}(0.8-2.0 \mathrm{ng} / \mathrm{mL})$ based on the Randomized Assessment of Digoxin on Inhibitors of the Angiotensin Converting Enzyme (RADIANCE) trial which studied 178 patients with heart failure [126]. These targets are largely based on toxicity rather than efficacy and definitively randomized control trials are absent. Additional retrospective analysis of the Prospective Randomized Study of Ventricular Failure and the Efficacy of Digoxin (PROVED) [127], RADIANCE and Digitalis Investigation Group (DIG) [128] trials supports that lower concentrations of 0.6$1.3 \mathrm{nmol} / \mathrm{L}(0.5-1.0 \mathrm{ng} / \mathrm{mL})$ are effective for treating heart failure [126]. More recent guidelines for management of 
heart failure also endorse these targets [129]. Other guidelines advise maximum trough concentrations of $1.5 \mathrm{nmol} / \mathrm{L}$ $(1.2 \mathrm{ng} / \mathrm{mL})$ for controlling heart rate in patient with atrial fibrillation where first-line therapies are ineffective [118]. Toxicity is better supported, with several studies identifying adverse effects at concentrations above $3.2 \mathrm{nmol} / \mathrm{L}$ $(2.5 \mathrm{ng} / \mathrm{mL})$ [130-133]. Recent guidelines suggest the use of TDM for digoxin purely to avoid toxicity given the paucity of evidence for efficacy [119].

Inter-method variability is an important consideration for digoxin TDM. Based on CAP proficiency testing survey data, the mean variability between methods ranges up to $28-40 \%$. The variability would effectively widen the therapeutic reference interval to $0.6-3.6 \mathrm{nmol} / \mathrm{L}$ (from 1 to $2.6 \mathrm{nmol} / \mathrm{L}$ ). The variability could potentially lead to toxicity at apparent therapeutic levels of digoxin.

\section{Summary}

Collectively, therapeutic reference intervals for many commonly monitored drugs are based on limited evidence. In particular, there are few if any randomized control trials demonstrating the efficacy of target concentrations. This is compounded by the lack of consideration of methodological differences in most of the available evidence and case reports. Moreover, variability in collection timing may contribute to uncertainty around the appropriate target values. While it is unlikely that there will be an investment in new studies for these older drugs, those interpreting the results should be aware of the limitations of the therapeutic targets and use available clinical signs and symptoms for monitoring individual patients. Algorithms, such as Bayesian approaches for aminoglycosides, may improve appropriate dosing. Awareness of the effect of co-morbidities and risks of polypharmacy are also important to avoid toxicity.

Given the variability, individuality and complexity of different patients, single target values in isolation are unlikely to serve the clinical need. Further, the small therapeutic window and potential overlap between therapeutic and toxic ranges mandate careful consideration during drug dosing in each patient. Guidelines and algorithmic, condition-specific target criteria are likely to better serve patients and help clinical users to achieve appropriate drug concentrations. Improvement and standardization of analytical methods may help improve consistency and interchangeability of therapeutic reference intervals.
Acknowledgments: I gratefully acknowledge the preliminary literature review performed by Amanda Owen.

Author contributions: The author has accepted responsibility for the entire content of this submitted manuscript and approved submission.

Research funding: None declared.

Employment or leadership: None declared.

Honorarium: None declared.

Competing interests: The funding organization(s) played no role in the study design; in the collection, analysis, and interpretation of data; in the writing of the report; or in the decision to submit the report for publication.

\section{References}

1. Kang J-S, Lee $\mathrm{M}-\mathrm{H}$. Overview of therapeutic drug monitoring. Korean J Intern Med 2009;24:1-10.

2. Touw DJ, Neef C, Thomson AH, Vinks AA; Cost-Effectiveness of Therapeutic Drug Monitoring Committee of the International Association for Therapeutic Drug Monitoring and Clinical Toxicology. Cost-effectiveness of therapeutic drug monitoring: a systematic review. Ther Drug Monit 2005;27:10-7.

3. Jannetto PJ, Bratanow NC. Pain management in the 21st century: utilization of pharmacogenomics and therapeutic drug monitoring. Expert Opin Drug Metab Toxicol 2011;7: 745-52.

4. Agrawal YP, Rennert H. Pharmacogenomics and the future of toxicology testing. Clin Lab Med 2012;32:509-23.

5. Al Za'abi M, Al Muqbali J, Al-Waili K. Sampling time and indications appropriateness for therapeutically monitored drugs at a teaching university hospital in Oman. Saudi Pharm J 2015;23:458-62.

6. Traugott KA, Maxwell PR, Green K, Frei C, Lewis JS. Effects of therapeutic drug monitoring criteria in a computerized prescriber-order-entry system on the appropriateness of vancomycin level orders. Am J Health Syst Pharm 2011;68:347-52.

7. Egan S, Murphy PG, Fennell JP, Kelly S, Hickey M, McLean C, et al. Using Six Sigma to improve once daily gentamicin dosing and therapeutic drug monitoring performance. BMJ Qual Saf 2012;21:1042-51.

8. Avent ML, Rogers BA, Cheng AC, Paterson DL. Current use of aminoglycosides: indications, pharmacokinetics and monitoring for toxicity. Intern Med J 2011;41:441-9.

9. Barclay ML, Begg EJ. Aminoglycoside toxicity and relation to dose regimen. Adverse Drug React Toxicol Rev 1994;13: 207-34.

10. Kumin GD. Clinical nephrotoxicity of tobramycin and gentamicin. A prospective study. J Am Med Assoc 1980;244:1808-10.

11. Lerner SA, Schmitt BA, Seligsohn R, Matz GJ. Comparative study of ototoxicity and nephrotoxicity in patients randomly assigned to treatment with amikacin or gentamicin. Am J Med 1986;80:98-104.

12. Evans WE, Schentag JJ, Jusko WJ. Applied pharmacokinetics: principles of therapeutic drug monitoring, 3rd ed. Vancouver, WA: Wolters Kluwer, 1992. 
13. Hammett-Stabler CA, Johns T. Laboratory guidelines for monitoring of antimicrobial drugs. Clin Chem 1998;44:1129-40.

14. Leis JA, Rutka JA, Gold WL. Aminoglycoside-induced ototoxicity. Can Med Assoc J 2015;187:E52.

15. Ahmed RM, Hannigan IP, MacDougall HG, Chan RC, Halmagyi GM. Gentamicin ototoxicity: a 23-year selected case series of 103 patients. Med J Aust 2012;196:701-4.

16. Moore RD, Lietman PS, Smith CR. Clinical response to aminoglycoside therapy: importance of the ratio of peak concentration to minimal inhibitory concentration. J Infect Dis 1987;155:93-9.

17. Nezic L, Derungs A, Bruggisser M, Tschudin-Sutter S, Krähenbühl S, Haschke $M$. Therapeutic drug monitoring of once daily aminoglycoside dosing: comparison of two methods and investigation of the optimal blood sampling strategy. Eur J Clin Pharmacol 2014;70:829-37.

18. Duffull SB, Kirkpatrick CM, Begg EJ. Comparison of two Bayesian approaches to dose-individualization for once-daily aminoglycoside regimens. Br J Clin Pharmacol 1997;43:125-35.

19. Burton ME, Ash CL, Hill DP, Handy T, Shepherd MD, Vasko MR. A controlled trial of the cost benefit of computerized bayesian aminoglycoside administration. Clin Pharmacol Ther 1991;49:685-94.

20. Bailey TC, Little JR, Littenberg B, Reichley RM, Dunagan WC. A meta-analysis of extended-interval dosing versus multiple daily dosing of aminoglycosides. Clin Infect Dis 1997;24:786-95.

21. Duszynska W, Taccone FS, Hurkacz M, Kowalska-Krochmal B, Wiela-Hojeńska A, Kübler A. Therapeutic drug monitoring of amikacin in septic patients. Crit Care 2013;17:R165.

22. van Altena R, Dijkstra JA, van der Meer ME, Borjas Howard JF, Kosterink JG, van Soolingen D, et al. Reduced chance of hearing loss associated with therapeutic drug monitoring of aminoglycosides in the treatment of multidrug-resistant tuberculosis. Antimicrob Agents Chemother 2017;61:e01400-16.

23. Jenkins A, Thomson AH, Brown NM, Semple Y, Sluman C, MacGowan A, et al. Amikacin use and therapeutic drug monitoring in adults: do dose regimens and drug exposures affect either outcome or adverse events? A systematic review. J Antimicrob Chemother 2016;71:2754-9.

24. Gooding PG, Berman E, Lane AZ, Agre K. A review of results of clinical trials with amikacin. J Infect Dis 1976;134:S441-5.

25. Hayward RS, Harding J, Molloy R, Land L, Longcroft-Neal K, Moore $\mathrm{D}$, et al. Adverse effects of a single dose of gentamicin in adults: a systematic review. $\mathrm{Br} J$ Clin Pharmacol 2018;84: 223-38.

26. Llanos-Paez CC, Hennig S, Staatz CE. Population pharmacokinetic modelling, Monte Carlo simulation and semi-mechanistic pharmacodynamic modelling as tools to personalize gentamicin therapy. J Antimicrob Chemother 2017;72:639-67.

27. Baddour LM, Wilson WR, Bayer AS, Fowler VG, Tleyjeh IM, Rybak MJ, et al. Infective endocarditis in adults: diagnosis, antimicrobial therapy, and management of complications: a scientific statement for healthcare professionals from the American Heart Association. Circulation 2015;132:1435-86.

28. Tunkel AR, Hasbun R, Bhimraj A, Byers K, Kaplan SL, Scheld WM, et al. 2017 Infectious Diseases Society of America's clinical practice guidelines for healthcare-associated ventriculitis and meningitis. Clin Infect Dis 2017;64:e34-e65.

29. Bratzler DW, Dellinger EP, Olsen KM, Perl TM, Auwaerter PG, Bolon MK, et al. Clinical practice guidelines for antimicrobial prophylaxis in surgery. Am J Health Syst Pharm 2013;70:195-283.
30. Rhodes A, Evans LE, Alhazzani W, Levy MM, Antonelli M, Ferrer $R$, et al. Surviving sepsis campaign: international guidelines for management of sepsis and septic shock: 2016. Intensive Care Med 2017;43:304-77.

31. Matzke GR, Burkle WS, Lucarotti RL. Gentamicin and tobramycin dosing guidelines: an evaluation. Drug Intell Clin Pharm 1983;17:425-32.

32. Gatell JM, San Miguel JG, Zamora L, Araujo V, Bonet M, Bohé M, et al. Comparison of the nephrotoxicity and auditory toxicity of tobramycin and amikacin. Antimicrob Agents Chemother 1983;23:897-901.

33. Freeman CD, Nicolau DP, Belliveau PP, Nightingale CH. Once-daily dosing of aminoglycosides: review and recommendations for clinical practice. J Antimicrob Chemother 1997;39:677-86.

34. Lee C, Walker SA, Walker SE, Seto W, Simor A, Jeschke M. A prospective study evaluating tobramycin pharmacokinetics and optimal once daily dosing in burn patients. Burns 2017;43:1766-74.

35. Barras MA, Serisier D, Hennig S, Jess K, Norris RL. Bayesian estimation of tobramycin exposure in patients with cystic fibrosis. Antimicrob Agents Chemother 2016;60:6698-702.

36. Chuk AC, Saeed F, Kousar N, Burrill S, Barns B, Rickrode G, et al. Variable pharmacokinetics of extended interval tobramycin or gentamicin among critically ill patients undergoing continuous venovenous hemofiltration. Clin Nephrol 2015;84:214-21.

37. Hammett-Stabler CA, Dasgupta A. Therapeutic drug monitoring data: a concise guide, 3rd ed. Washington, DC: AACC Press, 2007.

38. Rybak MJ, Albrecht LM, Boike SC, Chandrasekar PH. Nephrotoxicity of vancomycin, alone and with an aminoglycoside. J Antimicrob Chemother 1990;25:679-87.

39. Moellering RC Jr. Monitoring serum vancomycin levels: climbing the mountain because it is there? Clin Infect Dis 1994;18:544-6.

40. Geraci JE. Vancomycin. Mayo Clin Proc 1977;52:631-4.

41. Rybak M, Lomaestro B, Rotschafer JC, Moellering R, Craig W, Billeter $\mathrm{M}$, et al. Therapeutic monitoring of vancomycin in adult patients: a consensus review of the American Society of HealthSystem Pharmacists, the Infectious Diseases Society of America, and the Society of Infectious Diseases Pharmacists. Am J Health Syst Pharm 2009;66:82-98.

42. Neels HM, Sierens AC, Naelaerts K, Scharpé SL, Hatfield GM, Lambert WE. Therapeutic drug monitoring of old and newer antiepileptic drugs. Clin Chem Lab Med 2004;42:1228-55.

43. Sander JW. The use of antiepileptic drugs - principles and practice. Epilepsia 2004;45:28-34.

44. LaPenna P, Tormoehlen LM. The pharmacology and toxicology of third-generation anticonvulsant drugs. J Med Toxicol 2017;13:329-42.

45. Johannessen SI, Landmark CJ. Antiepileptic drug interactions - principles and clinical implications. Curr Neuropharmacol 2010;8:254-67.

46. Patsalos PN, Berry DJ, Bourgeois BF, Cloyd JC, Glauser TA, Johannessen $\mathrm{SI}$, et al. Antiepileptic drugs - best practice guidelines for therapeutic drug monitoring: a position paper by the subcommission on therapeutic drug monitoring, ILAE Commission on Therapeutic Strategies. Epilepsia 2008;49:1239-76.

47. Hitiris N, Brodie MJ. Evidence-based treatment of idiopathic generalized epilepsies with older antiepileptic drugs. Epilepsia 2005;46:149-53. 
48. Roin BN. Unpatentable drugs and the standards of patentability. Tex Rev 2009;87:504-69.

49. Perucca E. Clinically relevant drug interactions with antiepileptic drugs. Br J Clin Pharmacol 2006;61:246-55.

50. Feldman RG, Pippenger CE. The relation of anticonvulsant drug levels to complete seizure control. J Clin Pharmacol 1976;16:51-9.

51. Boeynaems J-M, De Leener A, Dessars B, Villa-Lobos HR, Aubry J-C, Cotton F, et al. Evaluation of a new generation of plastic evacuated blood-collection tubes in clinical chemistry, therapeutic drug monitoring, hormone and trace metal analysis. Clin Chem Lab Med 2004;42:67-71.

52. El-Dib M, Soul JS. The use of phenobarbital and other antiseizure drugs in newborns. Semin Fetal Neonatal Med 2017;22:321-7.

53. Au CC, Branco RG, Tasker RC. Management protocols for status epilepticus in the pediatric emergency room: systematic review article. J Pediatr 2017;93:84-94.

54. Tutor-Crespo MJ, Hermida J, Tutor JC. Relative proportions of serum carbamazepine and its pharmacologically active 10,11epoxy derivative: effect of polytherapy and renal insufficiency. Ups J Med Sci 2008;113:171-80.

55. Callaghan N, Kenny RA, O’Neill B, Crowley M, Goggin T. A prospective study between carbamazepine, phenytoin and sodium valproate as monotherapy in previously untreated and recently diagnosed patients with epilepsy. J Neurol Neurosurg Psychiatry 1985;48:639-44.

56. Troupin A, Ojemann LM, Halpern L, Dodrill C, Wilkus R, Friel P, et al. Carbamazepine - a double-blind comparison with phenytoin. Neurology 1977;27:511-9.

57. Reinikainen KJ, Keranen T, Halonen T, Komulainen H, Riekkinen PJ. Comparison of oxcarbazepine and carbamazepine: a doubleblind study. Epilepsy Res 1987;1:284-9.

58. Hiemke C, Bergemann N, Clement HW, Conca A, Deckert J, Domschke K, et al. Consensus guidelines for therapeutic drug monitoring in neuropsychopharmacology: update 2017. Pharmacopsychiatry 2018;51:9-62.

59. Shen S, Elin RJ, Soldin SJ. Characterization of cross reactivity by carbamazepine 10,11-epoxide with carbamazepine assays. Clin Biochem 2001;34:157-8.

60. Faero 0, Kastrup KW, Lykkegaard Nielsen E, Melchior JC, Thorn I. Successful prophylaxis of febrile convulsions with phenobarbital. Epilepsia 1972;13:279-85.

61. Buchthal F, Svensmark O, Simonsen H. Relation of eeg and seizures to phenobarbital in serum. Arch Neurol 1968;19:567-72.

62. Livingston S, Berman W, Pauli LL. Anticonvulsant drug blood levels: practical applications based on 12 years' experience. J Am Med Assoc 1975;232:60-2.

63. Touw DJ, Graafland O, Cranendonk A, Vermeulen RJ, van Weissenbruch MM. Clinical pharmacokinetics of phenobarbital in neonates. Eur J Pharm Sci 2000;12:111-6.

64. Waldman S. Pain review, 1st ed. Philadelphia, PA: Saunders, 2009.

65. Zaccara G, Messori A, Muscas GC, Albani F, Baruzzi A, Bianchi $A$, et al. Predictive performance of pharmacokinetic methods for phenytoin dosing: a multi-center evaluation in 282 patients with epilepsy. Epilepsy Res 1989;3:253-61.

66. Reynolds EH, Shorvon SD, Galbraith AW, Chadwick D, Dellaportas $\mathrm{Cl}$, Vydelingum L. Phenytoin monotherapy for epilepsy: a long-term prospective study, assisted by serum level monitoring, in previously untreated patients. Epilepsia 1981;22: 475-88.

67. Gram L, Bentsen KD, Parnas J, Flachs H. Controlled trials in epilepsy: a review. Epilepsia 1982;23:491-519.

68. Goodman LS, Hardman JG, Limbird LE, Gilman AG. Goodman and Gilman's the pharmacological basis of therapeutics, 10th ed. New York, USA: McGraw-Hill, Medical Pub. Division, 2001.

69. Matzke GR, Cloyd JC, Sawchuk RJ. Acute phenytoin and primidone intoxication: a pharmacokinetic analysis. J Clin Pharmacol 1981;21:92-9.

70. Woo E, Chan YM, Yu YL, Chan YW, Huang CY. If a well-stabilized epileptic patient has a subtherapeutic antiepileptic drug level, should the dose be increased? A randomized prospective study. Epilepsia 1988;29:129-39.

71. Schumacher GE, Barr JT, Browne TR, Collins JF. Test performance characteristics of the serum phenytoin concentration (SPC): the relationship between SPC and patient response. Ther Drug Monit 1991;13:318.

72. Hayes G, Kootsikas ME. Reassessing the lower end of the phenytoin therapeutic range: review of the literature. Ann Pharmacother 1993;27:1389-92.

73. Gallop K. Review article: phenytoin use and efficacy in the ED. Emerg Med Australas 2010;22:108-18.

74. Iwamoto T, Kagawa Y, Naito Y, Kuzuhara S, Okuda M. Clinical evaluation of plasma free phenytoin measurement and factors influencing its protein binding. Biopharm Drug Dispos 2006;27:77-84.

75. Booker HE, Darcey B. Serum concentrations of free diphenylhydantoin and their relationship to clinical intoxication. Epilepsia 1973;14:177-84.

76. Tutor-Crespo MJ, Hermida J, Tutor JC. Phenytoin immunoassay measurements in serum samples from patients with renal insufficiency: comparison with high-performance liquid chromatography. J Clin Lab Anal 2007;21:119-23.

77. Haughey DB, Matzke GR, Halstenson CE, Keane WF. Analytical specificity of commercially available methods for serum phenytoin determination. J Anal Toxicol 1984;8:106-11.

78. Villanelli F, Giocaliere E, Malvagia S, Rosati A, Forni G, Funghini $\mathrm{S}$, et al. Dried blood spot assay for the quantification of phenytoin using liquid chromatography-mass spectrometry. Clin Chim Acta 2015;440:31-5.

79. Garg U, Peat J, Frazee C, Nguyen T, Ferguson AM. A simple isotope dilution electrospray ionization tandem mass spectrometry method for the determination of free phenytoin. Ther Drug Monit 2013;35:831-5.

80. Peat J, Frazee C, Garg U. Quantification of free phenytoin by liquid chromatography tandem mass spectrometry (LC/MS/MS). Methods Mol Biol 2016;1383:241-6.

81. Lenn NJ, Robertson M. Clinical utility of unbound antiepileptic drug blood levels in the management of epilepsy. Neurology 1992;42:988-90.

82. Gidal BE, Pitterle ME, Spencer NW, Maly MM. Relationship between valproic acid dosage, plasma concentration and clearance in adult monotherapy patients with epilepsy. J Clin Pharm Ther 1995;20:215-9.

83. Haroldson JA, Kramer LE, Wolff DL, Lake KD. Elevated free fractions of valproic acid in a heart transplant patient with hypoalbuminemia. Ann Pharmacother 2000;34:183-7. 
84. Sundqvist A, Tomson T, Lundkvist B. Pharmacokinetics of valproic acid in patients with juvenile myoclonic epilepsy on monotherapy. Ther Drug Monit 1997;19:153-9.

85. Gram L, Flachs H, Würtz-Jørgensen A, Parnas J, Andersen B. Sodium valproate, serum level and clinical effect in epilepsy: $a$ controlled study. Epilepsia 1979;20:303-11.

86. Turnbull DM, Howel D, Rawlins MD, Chadwick DW. Which drug for the adult epileptic patient: phenytoin or valproate? Br Med J 1985;290:815-9.

87. Shipkova M, Hesselink DA, Holt DW, Billaud EM, van Gelder T, Kunicki PK, et al. Therapeutic drug monitoring of everolimus: a consensus report. Ther Drug Monit 2016;38:143.

88. Seger C, Shipkova M, Christians U, Billaud EM, Wang P, Holt DW, et al. Assuring the proper analytical performance of measurement procedures for immunosuppressive drug concentrations in clinical practice: recommendations of the International Association of Therapeutic Drug Monitoring and Clinical Toxicology Immunosuppressive Drug Scientific Committee. Ther Drug Monit 2016;38:170.

89. Christians U, Vinks AA, Langman LJ, Clarke W, Wallemacq P, van Gelder T, et al. Impact of laboratory practices on interlaboratory variability in therapeutic drug monitoring of immunosuppressive drugs. Ther Drug Monit 2015;37:718.

90. Sallustio BC. LC-MS/MS for immunosuppressant therapeutic drug monitoring. Bioanalysis 2010;2:1141-53.

91. McShane AJ, Bunch DR, Wang S. Therapeutic drug monitoring of immunosuppressants by liquid chromatography-mass spectrometry. Clin Chim Acta 2016;454:1-5.

92. Aucella F, Lauriola V, Vecchione G, Tiscia GL, Grandone E. Liquid chromatography-tandem mass spectrometry method as the golden standard for therapeutic drug monitoring in renal transplant. J Pharm Biomed Anal 2013;86:123-6.

93. Mika A, Stepnowski P. Current methods of the analysis of immunosuppressive agents in clinical materials: a review. J Pharm Biomed Anal 2016;127:207-31.

94. Annesley TM, McKeown DA, Holt DW, Mussell C, Champarnaud E, Harter L, et al. Standardization of LC-MS for therapeutic drug monitoring of tacrolimus. Clin Chem 2013;59:1630-7.

95. Mármol F. Lithium: 55 years of history in the therapy of bipolar affective disorder. Med Clin 2006;127:189-95.

96. Cade JF. Lithium salts in the treatment of psychotic excitement. Med J Aust 1949;2:349-52.

97. Machado-Vieira R. Lithium, stress, and resilience in bipolar disorder: deciphering this key homeostatic synaptic plasticity regulator. J Affect Disord 2018;233:92-9.

98. Grandjean EM, Aubry J-M. Lithium: updated human knowledge using an evidence-based approach. Part II: clinical pharmacology and therapeutic monitoring. CNS Drugs 2009;23:331-49.

99. Gupta S, Khastgir U. Drug information update. Lithium and chronic kidney disease: debates and dilemmas. BJPsych Bull 2017;41:216-20.

100. Ward ME, Musa MN, Bailey L. Clinical pharmacokinetics of lithium. J Clin Pharmacol 1994;34:280-5.

101. Gitlin M. Lithium side effects and toxicity: prevalence and management strategies. Int J Bipolar Disord 2016;4:27.

102. Finley PR. Drug interactions with lithium: an update. Clin Pharmacokinet 2016;55:925-41.
103. Malhi GS, Gessler D, Outhred T. The use of lithium for the treatment of bipolar disorder: recommendations from clinical practice guidelines. J Affect Disord 2017;217:266-80.

104. American Psychiatric Association. Practice guideline for the treatment of patients with bipolar disorder (revision). Am J Psychiatry 2002;159:1-50.

105. Mohandas E, Rajmohan V. Lithium use in special populations. Indian J Psychiatry 2007;49:211-8.

106. D’Souza R, Rajji TK, Mulsant BH, Pollock BG. Use of lithium in the treatment of bipolar disorder in late-life. Curr Psychiatry Rep 2011;13:488-92.

107. Ewy GA. Digoxin: the art and science. Am J Med 2015;128:1272-4.

108. Wolf P. Creativity and chronic disease Vincent van Gogh (1853-1890). West J Med 2001;175:348.

109. Wolf PL. If clinical chemistry had existed then.... Clin Chem 1994:40:328-35.

110. Ehle M, Patel C, Giugliano RP. Digoxin: clinical highlights: a review of digoxin and its use in contemporary medicine. Crit Pathw Cardiol 2011;10:93-8.

111. Gelbart A, Hall RJ, Goldman RH. Digoxin-induced arrhythmias in hypokalaemia. Lancet 1976;2:850-1.

112. Chan BS, Buckley NA. Digoxin-specific antibody fragments in the treatment of digoxin toxicity. Clin Toxicol Phila Pa 2014;52:824-36.

113. Alpert JS. To Dig or Not to Dig. Am J Med 2014;127:461-2.

114. Ziff OJ, Kotecha D. Digoxin: the good and the bad. Trends Cardiovasc Med 2016;26:585-95.

115. Ziff OJ, Lane DA, Samra M, Griffith M, Kirchhof P, Lip GY, et al. Safety and efficacy of digoxin: systematic review and meta-analysis of observational and controlled trial data. $\mathrm{Br}$ Med J 2015;351:h4451.

116. Ponikowski P, Voors AA, Anker SD, Bueno H, Cleland JG, Coats AJ, et al. 2016 ESC guidelines for the diagnosis and treatment of acute and chronic heart failure: the task force for the diagnosis and treatment of acute and chronic heart failure of the European Society of Cardiology (ESC). Developed with the special contribution of the Heart Failure Association (HFA) of the ESC. Eur Heart J 2016;37:2129-200.

117. Rifai N. Tietz textbook of clinical chemistry and molecular diagnostics, 6th ed. St. Louis, Missouri: Elsevier Canada, 2017

118. Macle L, Cairns J, Leblanc K, Tsang T, Skanes A, Cox JL, et al. 2016 Focused Update of the Canadian Cardiovascular Society Guidelines for the Management of Atrial Fibrillation. Can J Cardiol 2016;32:1170-85.

119. Ezekowitz JA, O'Meara E, McDonald MA, Abrams H, Chan M, Ducharme A, et al. 2017 Comprehensive Update of the Canadian Cardiovascular Society Guidelines for the Management of Heart Failure. Can J Cardiol 2017;33: 1342-433.

120. Valdes R. Endogenous digoxin-like immunoreactive factors: impact on digoxin measurements and potential physiological implications. Clin Chem 1985;31:1525-32.

121. Lampon N, Pampin F, Tutor JC. Investigation of possible interference by digoxin-like immunoreactive substances on the Architect iDigoxin CMIA in serum samples from pregnant women, and patients with liver disease, renal insufficiency, critical illness, and kidney and liver transplant. Clin Lab 2012;58:1301-4. 
122. Way BA, Wilhite TR, Miller R, Smith CH, Landt M. Vitros digoxin immunoassay evaluated for interference by digoxin-like immunoreactive factors. Clin Chem 1998;44:1339-40.

123. McMillin GA, Owen WE, Lambert TL, De BK, Frank EL, Bach PR, et al. Comparable effects of DIGIBIND and DigiFab in thirteen digoxin immunoassays. Clin Chem 2002;48:1580-4.

124. George S, Braithwaite RA, Hughes EA. Digoxin measurements following plasma ultrafiltration in two patients with digoxin toxicity treated with specific Fab fragments. Ann Clin Biochem 1994;31:380-1.

125. Jortani SA, Pinar A, Johnson NA, Valdes R. Validity of unbound digoxin measurements by immunoassays in presence of antidote (Digibind). Clin Chim Acta 1999;283:159-69.

126. Terra SG, Washam JB, Dunham GD, Gattis WA. Therapeutic range of digoxin's efficacy in heart failure: what is the evidence? Pharmacotherapy 1999;19:1123-6.

127. Tauke J, Goldstein S, Gheorghiade M. Digoxin for chronic heart failure: a review of the randomized controlled trials with special attention to the PROVED (Prospective Randomized Study of Ventricular Failure and the Efficacy of Digoxin) and RADIANCE (Randomized Assessment of Digoxin on Inhibitors of the angiotensin Converting Enzyme) trials. Prog Cardiovasc Dis 1994;37:49-58.

128. Digitalis Investigation Group. The effect of digoxin on mortality and morbidity in patients with heart failure. N Engl J Med 1997;336:525-33.

129. Yancy CW, Jessup M, Bozkurt B, Butler J, Casey DE, Drazner $\mathrm{MH}$, et al. 2013 ACCF/AHA guideline for the management of heart failure: a report of the American College of Cardiology Foundation/American Heart Association Task Force on Practice Guidelines. Circulation 2013;128:e240-327.

130. Ingelfinger JA, Goldman P. The serum digitalis concentration does it diagnose digitalis toxicity? N Engl J Med 1976;294: 867-70.

131. Smith TW, Haber E. Digoxin intoxication: the relationship of clinical presentation to serum digoxin concentration. J Clin Invest 1970;49:2377-86.

132. Beller GA, Smith TW, Abelmann WH, Haber E, Hood WB. Digitalis intoxication. A prospective clinical study with serum level correlations. N Engl J Med 1971;284:989-97.

133. Evered DC, Chapman C. Plasma digoxin concentrations and digoxin toxicity in hospital patients. Br Heart J 1971;33:540-5. 